\title{
Improving probabilistic flood forecasting through a data assimilation scheme based on genetic programming
}

\author{
L. Mediero, L. Garrote, and A. Chavez-Jimenez \\ Technical University of Madrid, Department of Civil Engineering, Hydraulic and Energy Engineering, Madrid, Spain \\ Correspondence to: L. Mediero (luis.mediero@upm.es) \\ Received: 16 November 2011 - Revised: 28 June 2012 - Accepted: 18 September 2012 - Published: 19 December 2012
}

\begin{abstract}
Opportunities offered by high performance computing provide a significant degree of promise in the enhancement of the performance of real-time flood forecasting systems. In this paper, a real-time framework for probabilistic flood forecasting through data assimilation is presented. The distributed rainfall-runoff real-time interactive basin simulator (RIBS) model is selected to simulate the hydrological process in the basin. Although the RIBS model is deterministic, it is run in a probabilistic way through the results of calibration developed in a previous work performed by the authors that identifies the probability distribution functions that best characterise the most relevant model parameters. Adaptive techniques improve the result of flood forecasts because the model can be adapted to observations in real time as new information is available. The new adaptive forecast model based on genetic programming as a data assimilation technique is compared with the previously developed flood forecast model based on the calibration results. Both models are probabilistic as they generate an ensemble of hydrographs, taking the different uncertainties inherent in any forecast process into account. The Manzanares River basin was selected as a case study, with the process being computationally intensive as it requires simulation of many replicas of the ensemble in real time.
\end{abstract}

\section{Introduction}

Hydrological flood forecasting entails estimation of a hydrological variable in the future from the available data in the present and the set of recorded data of flood events in the past, giving its time of occurrence, quantitative measure and reliability (Szöllösi-Nagy, 2009). The utility of a hydrological forecast increases, given that its uncertainty is better quantified either by a probability distribution of occurrence or by an ensemble of possible scenarios. Uncertainty bounds must be defined (with the potential adverse consequences) to assist flood managers and users so that they can make decisions taking risk into account (Komma et al., 2007).

Information about historic flood events in the past is not sufficient to fully characterise the hydrological behaviour of the basin in the future. In addition, a fixed model with constant parameters will not be able to represent completely the complex processes in the basin. For practical purposes, an adaptive forecast scheme may be used to adjust model parameters, state variables and/or specify results of changes in the basin behaviour that cannot be simulated by the initial model setup (Young, 2002). Adaptive forecasting techniques have been applied to forecasting water levels in the River Severn in the United Kingdom (Romanowicz et al., 2006); forecasting floods in regulated basins in Korea, therefore improving the forecast of the high-flow events (Shamir et al., 2010); improving flood forecasts in the Rhine and Meuse rivers (Weerts et al., 2010); and improving streamflow forecasts in France, mainly for small basins (Thirel et al., 2010).

Data assimilation techniques can be used to develop an adaptive forecast model, as they update estimates of system states or parameters quantifying errors in both the hydrological model and observations. Therefore, data assimilation can improve flood forecasts (Vrugt et al., 2006). Furthermore, data assimilation applied to a distributed hydrological model has significant potential, as model estimates of basin states can be improved from observations at a gauged station keeping their distribution in space (Liu and Gupta, 2007; Clark et al., 2008).

Data assimilation techniques have been extensively applied in the atmospheric and oceanic sciences, though their application to hydrology is relatively new. The first models 
were based on the Kalman filter (KF) technique (Kalman, 1960), which is used to update the model state variables from the assimilation of observed discharge data, extending the model and observed data uncertainties to uncertainties in the forecast (Bras and Rodriguez-Iturbe, 1985; Awwad and Valdés, 1992).

The extended Kalman filter (EKF) linearises the error covariance equation and propagates the covariance matrix in the future. Although it is effective in many cases, it is unstable if the nonlinearities are strong and it fails in representing the error probability (Reichle and Koster, 2003). To solve this unstable behaviour, a filter based on Monte-Carlo simulations has been developed, termed the ensemble Kalman filter (EnKF) (Evensen, 2003, 2004), which generates an ensemble of forecasts from a set of model states that take model and observed data uncertainties into account. The model is updated with the variance of the ensemble prediction from differences between each ensemble member and the ensemble mean. EnKF has been widely applied as a result of recent increases in computing capacity, making the approach affordable (Pauwels and De Lannoy, 2006; Shamir et al., 2010).

Kalman filters assume that the prior distribution of model states is represented by a Gaussian distribution, though state variables in hydrology do not always follow a Gaussian distribution. Particle filter (PF) techniques do not assume any prior distribution, at the expense of requiring a larger number of ensembles. PF assigns a probability to each ensemble element by a weight calculated as the difference between the ensemble element and the observations (Moradkhani et al., 2005; Weerts and El Serafy, 2006). Furthermore, Kalman filters assume that the model parameters are known prior to the forecast. This is not the case for hydrological forecasts, however, as rainfall-runoff models use parameters that represent either physical or conceptual properties of runoff processes that cannot be accurately estimated and model outputs highly depend on these parameters. Moreover, some model parameters may not be stationary because the basin can change its behaviour during a given flood event, with data assimilation techniques being able to change its estimate of model parameters in real time.

Genetic programming (GP) is a suitable technique in adapting model parameters to observations, given that it is designed to identify and enhance good individuals from an ensemble by applying selection and crossover techniques. GP is an evolutionary algorithm (EA), which includes a set of techniques inspired by biological evolution that simulate the evolution of individuals by means of different perturbations and a fitness function, such as the following: (a) genetic algorithms used to solve optimisation problems (Holland, 1975); (b) evolutionary programming (that is very similar to GP but uses a fixed structure of the problem) (Fogel et al., 1966); (c) evolution strategy that works with vectors or real numbers and uses self-adaptive mutation rates (Schwefel, 1981); (d) GP that work with trees; and (e) Neuroevolution that uses artificial neural networks to represent the variables (Angeline, 1994).

GP uses the Darwinian natural selection principle of survival and reproduction of the best individuals (from an initial population the best individuals are selected with a fitness function) (Koza, 1992). These so-called better individuals are chosen to breed the next generation, applying certain perturbations. The new individuals fight to survive in the next generation, with the process being repeated based on perturbations to create diversity and selection to improve the fitness (Eiben and Smith, 2007).

GP has been used in hydrology in a diversity of applications. For example, a GP system was used to discover rainfall-runoff relationships in different basins from daily time series of rainfall-runoff data and a lumped model based on the unit hydrograph technique. The GP model led to a more robust model than the conventional ones (especially when surface runoff processes and precipitation losses were not correctly understood) (Whigham and Crapper, 2001). A data-driven model based on GP was developed from hydrometeorological data to avoid the problem of collecting data of physically-based models and to overcome the problem of formulating traditional models to describe the non-linear processes of runoff generation (Babovic and Keijzer, 2002). Both were successful approaches and improved the conventional models.

Khatibi et al. (2011) compared three artificial intelligence techniques to simulate the discharge routing process: artificial neural networks (ANN), adaptive neuro-fuzzy inference system (ANFIS) and GP. The latter showed an improved performance in most of the assessment measures. Elshorbagy et al. (2010a and b) compared seven data-driven techniques in a modelling experiment: ANN, GP, evolutionary polynomial regression, support vector machines, M5 model trees, $\mathrm{K}$-nearest neighbours and multiple-linear regression. GP was also the most successful technique in terms of predictive accuracy and uncertainties due to its ability to adapt the model to the data. In addition, Wang et al. (2009a) conducted a comparison to forecast monthly discharge time series, where the GP and ANFIS models obtained the better results, though the former achieved the best forecast results in the validation phase.

Other comparisons have been conducted in the following cases: to identify the unit hydrograph of an urban basin, where the results were improved by using GP to obtain mathematical expressions that correct the model errors (Rabunal et al., 2007); to simulate rainfall-runoff processes, enabling GP techniques to provide a useful tool in solving problems in hydrology by means of a simple and explicit model (Aytek and Alp, 2008); to improve the reliability of hydrologic prediction, showing that GP models can be used to predict the model uncertainty (Parasuraman and Elshorbagy, 2008); and finally, to develop a flow prediction method, where the usefulness of a GP model as an effective algorithm to forecast the long-term discharges was demonstrated (Savic et al., 
1999; Wang et al., 2009b). In addition to the aforementioned cases, the GP technique was also applied to real-time forecasting (Khu et al., 2001; Kisi and Shiri, 2011).

This paper presents the development of an adaptive flood forecast model. A sequential data assimilation technique is developed to update the estimation of the probability distribution of several parameters of a distributed rainfall-runoff model. The stochastic parameter estimation is performed by application of a GP algorithm to minimise the expected value of model errors. The paper is organised as follows: Sect. 2 presents the methodology to develop the adaptive flood forecast model; Sect. 3 introduces the case study used to test the model; Sect. 4 is devoted to discuss the results of the model in a set of flood events; and finally, the conclusions are presented in Sect. 5.

\section{Methodology}

A hydrological forecast model estimates the response of a basin from the current observations and predictions of future meteorological conditions. As new observations are available in real time, this information can be used to update the model by data assimilation techniques. This paper focuses on the evaluation of the benefits of a data assimilation technique based on GP from a forecast without data assimilation.

This section is organised in five parts. First the rainfallrunoff model is presented, then the forecast scheme without data assimilation is described and finally the proposed forecast scheme with data assimilation is introduced.

\subsection{Rainfall-runoff model}

The methodology is applied to the real-time interactive basin simulator (RIBS) model (Garrote and Bras, 1995a and b). Such a model is composed of a runoff-generation module that estimates the infiltration capacity and obtains the evolution of the saturated area of the basin, as well as a flow routing module that propagates discharge across the basin. Two processes are represented in the runoff-generation module: local infiltration and lateral moisture fluxes. It is assumed that the saturated hydraulic conductivity $\left(K_{\mathrm{S}}\right)$ decreases with soil depth $(z)$ following an exponential function. The soil is considered anisotropic, with $K_{\mathrm{s}}$ varying in directions normal $(n)$ and parallel $(p)$ to the sloped soil surface according to the following equations:

$$
\begin{aligned}
& K_{\mathrm{S}_{n}}(z)=K_{0 n} \mathrm{e}^{-f z}\left(\frac{\theta-\theta_{\mathrm{r}}}{\theta_{\mathrm{s}}-\theta_{\mathrm{r}}}\right)^{\varepsilon} \\
& K_{\mathrm{s}_{p}}(z)=K_{0 p} \mathrm{e}^{-f z}\left(\frac{\theta-\theta_{\mathrm{r}}}{\theta_{\mathrm{s}}-\theta_{\mathrm{r}}}\right)^{\varepsilon},
\end{aligned}
$$

where $K_{0 n}$ and $K_{0 p}\left(\mathrm{~mm} \mathrm{~h}^{-1}\right)$ are the saturated hydraulic surface conductivities in directions normal and parallel to the surface; $f\left(\mathrm{~mm}^{-1}\right)$ a parameter that controls the reduction of saturated hydraulic conductivity with depth; $\theta$ the soil moisture content; $\theta_{\mathrm{r}}$ the residual soil moisture content; $\theta_{\mathrm{S}}$ the saturated moisture content; and $\varepsilon$ the index of soil porosity.

The saturated hydraulic surface conductivities in the parallel and normal directions are related by the anisotropy coefficient $(a)$ :

$a=\frac{K_{0 p}}{K_{0 n}}$.

Under the kinematic approximation, the contribution of capillary forces to pore pressure is neglected (Beven, 1984). This leads to the establishment of a wetting front: a sharp discontinuity that separates two areas with different moisture content; the upper zone contains the moisture wave of the storm and the lower zone remains with the initial soil moisture content. The depth of the wetting front is represented by the variable $N_{f}(\mathrm{~mm})$. If saturation is reached, there is also an upper front representing the ascension of the saturated zone, $N_{t}(\mathrm{~mm})$. Normal flow in this area, $q_{n}\left(\mathrm{~mm} \mathrm{~h}^{-1}\right)$, is given by

$q_{n}=K_{0 n} \frac{f\left(N_{f}-N_{t}\right)}{e^{f N_{f}}-e^{f N_{t}}}$.

Surface runoff will occur when the value of rainfall intensity exceeds the infiltration capacity of the soil, or when the soil is saturated.

The flow routing module simulates the runoff propagation process through the basin. Flow routing is based on the distributed convolution equation:

$Q(t)=\int_{A} \int_{0}^{t} R_{f}(x, y, \tau) h(x, y, t-\tau) d \tau d A$,

where $Q(t)$ is the resulting hydrograph at the outlet, $R_{f}(x, y, t)$ is a function describing the distribution of runoff rate generation per unit area and $h(x, y, t)$ is the instantaneous response function of the element of area $d A$ located at coordinates $(x, y)$. The estimation of the instantaneous response function is based on travel time along the flow path, assuming constant velocities on the hillslopes $\left(v_{\mathrm{h}}\right)$ and on the riverbeds $\left(v_{\mathrm{s}}\right)$. To account for possible non-linearities, stream velocity, $v_{\mathrm{s}}$, may grow with the relative value of flow at the discharge point of the basin, $Q(t)$, with respect to a reference flow rate $Q_{\text {ref }}$, with the exponent $r$ :

$v_{\mathrm{S}}(t)=C_{\mathrm{v}}\left[\frac{Q(t)}{Q_{\mathrm{ref}}}\right]^{r}$.

If the exponent is taken as equal to $0, v_{\mathrm{s}}$ is constant throughout the simulation. For $r>0$, the channel velocity is greater than the parameter $C_{\mathrm{v}}\left(\mathrm{m} \mathrm{s}^{-1}\right)$ when the discharge at the outlet is above the reference value and otherwise smaller than $C_{\mathrm{v}}$. Hillslope velocity is defined as a function of stream velocity through a dimensionless parameter, $K_{\mathrm{v}}$ :

$v_{\mathrm{h}}(t)=\frac{v_{\mathrm{s}}(t)}{K_{\mathrm{v}}}$. 


\subsection{Forecast without data assimilation}

The forecast model without data assimilation does not take advantage of the possibilities to adapt its parameters to discharge observations in real time, as it is based on the results of a calibration process developed prior to the occurrence of the event. However, it is formulated as an ensemble forecast to take the forecast uncertainty into account. Ensemble models were developed to assess the forecast uncertainty with a low number of simulations and have shown their advantages over other techniques for operational forecasting (Rebora et al., 2006; Dietrich et al., 2009).

Forecast ensemble members are generated by sampling from the probability distributions of relevant model parameters. The probabilistic calibration developed by Mediero et al. (2011) was applied to obtain the initial estimation of the probability distribution of model parameters. This approach was selected as it takes into account that hydrological models are unable to provide a unique combination of parameters that correctly simulate all situations that may occur in the basin due to: (a) the presence of structural errors (Wagener et al., 2004); (b) a set of multiple parameters leading to an interval of forecast discharges that provides a better assessment of the forecast uncertainties (Beven, 2006); and (c) addressing of the uncertainty involved in the forecast being crucial (Taramasso et al., 2005).

\subsubsection{Probabilistic calibration}

The probabilistic calibration of the RIBS rainfall-runoff model in the Manzanares River basin was carried out in Mediero et al. (2011). A summary of this calibration is presented in this section.

The model calibration started with a sensitivity analysis of the RIBS model parameters to find the most influential parameters on model results in order to reduce the number of parameters used in the calibration process. Three parameters were identified as the most influential on the model results: parameter $f$, which represents the variation of hydraulic conductivity with respect to depth; parameter $K_{\mathrm{v}}$, which represents the ratio between flow velocity and hillslope velocity in the riverbed; and parameter $C_{\mathrm{v}}$, which represents a coefficient of the law that simulates the relationship between velocity on the riverbed and discharge at the outlet of the basin.

Then, a set of objective functions were selected to assess the most important aspects of the hydrograph in a flood forecast. The hydrograph was divided into two parts according to the mean flow value: $\mathrm{P}$ at the end of the objective function means the upper part, and B the lower part. Four objective functions were selected: the shape of the hydrograph in its upper part analysed by the root mean squared error applied to the upper part of the hydrograph (RMSE-P); the magnitude of low flows analysed by the mean absolute error applied to its lower part (MAE-B); the utility of the hydrograph as a forecast analysed by the Nash-Sutcliffe efficiency coefficient
(NSE); and the time of occurrence of the peak analysed by the time to peak (TP) objective function.

A multi-objective calibration of the model was performed to find the set of parameter combinations that lead to the most accurate solutions, based on the Pareto solutions calculated as the set of non-dominated optimal solutions. The multiobjective calibration entailed three steps. In the first step, the Pareto solutions were obtained with the four selected objective functions to identify the range of values of $C_{\mathrm{v}}$ that leads to an accurate simulated peak time. In the second, the Pareto solutions were obtained from RMSE-P, MAE-B and NSE, identifying the parameter combinations that lead to an accurate simulation of the upper part of the hydrograph. And in the third, the solutions obtained in the second step that fall outside the validity range of $C_{\mathrm{v}}$ obtained in the first step were eliminated. Finally, the solutions that properly simulate the shape and peak time simultaneously were identified as calibration results with ranges that are physically meaningful.

A distribution function is fitted to the resulting populations of each parameter. A beta function was fitted to the logarithmic values of parameter $f$ :

$\log _{10}(f)=-3.15+2.85 \times f_{\text {beta }}(\alpha=2.43, \beta=1.75)$

Parameter $K_{\mathrm{v}}$ was represented by a Weibull function with parameters $\alpha=8.82$ and $\beta=7.78$. Parameter $C_{\mathrm{v}}$ was represented by a normal distribution function with a mean $(\mu)$ of 1.883 and a standard deviation $(\sigma)$ of 0.097 . Independence between parameters was studied and it was found that independence between parameters can be assumed. Therefore, the result of the calibration process is a set of parameter combinations randomised from these fitted functions; that is to say, the calibration result is a probability density function for each parameter instead of a unique solution.

\subsubsection{Forecast model}

This first forecast model does not use data assimilation techniques, ignoring the new discharge observations in real-time. The model is fixed prior to the forecast from the result of the probabilistic calibration and cannot adapt itself to changes in the basin response or to forecast errors.

A set of parameter combinations is generated with the distribution functions that represent the variability of each parameter after the calibration process. The model initial condition was selected among a set of previously computed basin states, obtained as the water table depths that are in long-term equilibrium with a given constant recharge rate. The moisture profile in the unsaturated zone is defined to reach saturation at the water table depth, as suggested in Cabral et al. (1992). The choice of initial basin state depends on antecedent conditions prior to the storm, and introduces additional uncertainty to the forecasting process. In each time step, as new rainfall observations are available, the model is run with these fixed parameters to simulate the basin response to the observed 
rainfall up to current time and then run into the future with alternative rainfall forecasts from different sources. A large fraction of model uncertainty is linked to uncertainties in the forecast rainfall. Testing the validity of these rainfall forecasts is beyond the scope of this paper, given that the aim is testing the hydrological forecast models, not the rainfall forecasts. Therefore, the forecast model was used in hindcast mode, assuming perfect knowledge of future rainfall, although emulating real-time operation. Other sources of uncertainty, such as those corresponding to the choice of initial condition, cannot be eliminated without data assimilation.

\subsection{Forecast with data assimilation}

The second forecast model is based on the application of GP as a data assimilation technique to adapt the model to new observations during the flood event in order to improve the first flood forecast model.

The forecast model based on GP takes the result of the calibration process and the initial condition used in the forecast model without assimilation as a starting point and adapts the individuals of this first population of parameters with the new available records in each operational time step. Although the comparison between models was conducted with the same initial population, it could also be conducted with two different randomisations from the result of the probabilistic calibration without any significant influence on the comparison results. The data assimilation scheme is based on updating model parameter values, and therefore only one initial basin state was considered. A similar approach could be applied taking several basin states as initial condition. This approach was not considered to allow for a better comparison with respect to the forecast without data assimilation, where the full ensemble of model parameters was used, but only one initial basin state. The procedure used by the forecast model based on GP can be summarised as follows:

1. Generation of an initial population of parameter combinations from a randomisation with the results of the probabilistic calibration.

2. Running of the RIBS model with this initial population of parameters in the first time step, taking the observed rainfall in this first time step as an input and obtaining an ensemble of simulations as an output.

3. Quantifying the ability to reproduce the observed hydrograph of each individual of the ensemble population by an objective function that evaluates the fit between simulated and observed discharges.

4. Selection of the set of best individuals or parameter combinations of the ensemble from the results of the previous step. These individuals will live in the next time step and are termed the mating population.
5. Mating of the selected individuals of the ensemble, applying the crossover technique or exchange of parameter values between them.

6. Mating of the selected individuals of the ensemble, applying the mutation technique or random perturbation of the parameter values of an individual.

7. Creation of the next generation of individuals or children, joining the mating population or selected parameter combinations in step four and the result of the crossover in step five and the result of the mutation in step six.

8. Repetition of steps two to seven up to the end of the hydrograph, taking the ensemble population of model parameters obtained in the step seven as initial population.

The steps of selection (two through four), crossover (five) and mutation (six) are described in detail as follows.

\subsubsection{Selection}

Selection consists of identifying the best individuals that will survive in the next generation. An individual or parameter combination is better than another when the former leads to a better representation of the observed hydrograph than the latter. Therefore, a probability to survive the next generation is assigned to each parameter combination from its ability to represent the hydrological response of the basin. The parameter combinations are evaluated, punishing the parameter combinations and basin states that lead to less accurate results and rewarding the parameter combinations and basin states that lead to better results. The ability of an individual is evaluated by an objective function. A fitness ranking was selected to assign the survival probability and parameter combinations are sorted by their values of the objective function. The root mean squared error (RMSE) was selected as an objective function as it gives a higher penalty to higher errors:

$\operatorname{RMSE}\left(\theta_{i}\right)=\sqrt{\frac{1}{N} \sum_{t=1}^{N}\left(y_{t}-y_{t}^{\prime}\left(\theta_{i}\right)\right)^{2}}$,

where $y_{t}$ is the observed flow at time $t, y_{t}^{\prime}\left(\theta_{i}\right)$ is the simulated flow at time $t$ with parameters $\theta_{i}$, with $i$ being the $i$-th simulation, and $N$ the number of time steps used in the evaluation, which in this case is equal to eight, as an evaluation period of two hours is used.

The selected individuals are the parents that mate and produce the children in the next generation by crossover and mutation processes.

\subsubsection{Crossover}

Crossover process consists in producing a new offspring of parameter combinations from interchanging genetic material 

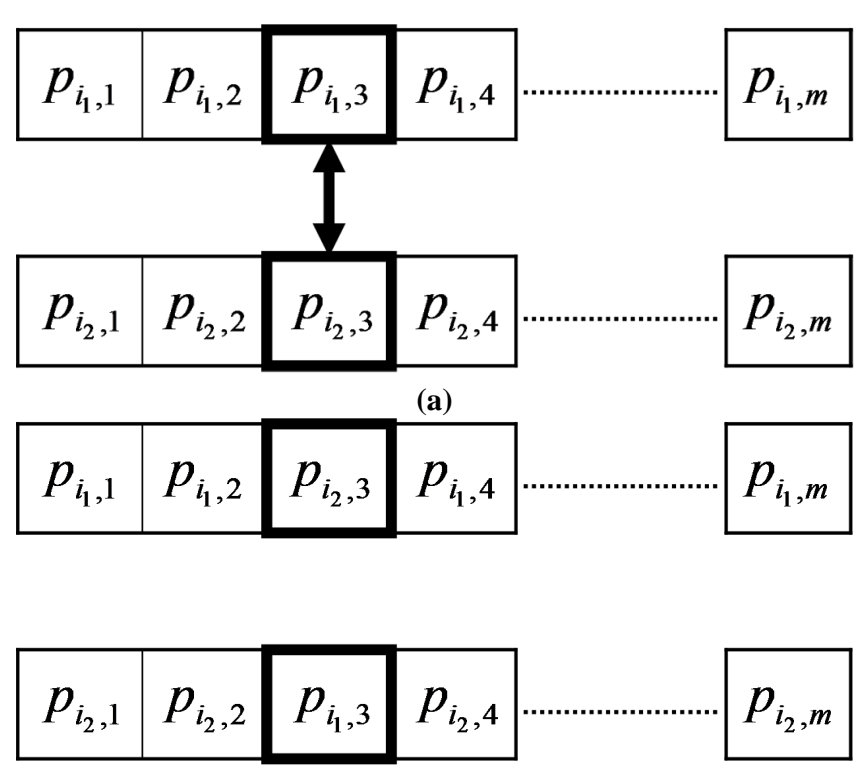

(b)

Fig. 1. Scheme of the crossover process: (a) parents; (b) children.

or parameter values between two parents. The new children inherit the parameter values of their two parents, though they do not have exactly the same characteristics as either of them, given that a genetic exchanging occurs in the process. The crossover process follows the principle that part of the offspring obtained by mating two individuals with different characteristics will improve the properties of their parents, while the rest will have worse properties than their parents. Natural selection is responsible for selecting the better individuals and improving the quality of the next generation. The improved offspring will then have a higher probability of surviving the next generation.

Crossover is based on a stochastic process (Fig. 1). From the ensemble of model parameter combinations, $p_{i, j}$, where $i$ is $i$-th ensemble simulation and $j$ is $j$-th model parameter, with $m$ the number of model parameters, two parameter combinations are taken randomly from the ensemble ( $i_{1}$ and $i_{2}$ in the example shown in Fig. 1). Then, a model parameter is selected randomly from the $m$ model parameters (the third parameter in the example shown in Fig. 1). The parameter value of the first parameter combination $\left(p_{i_{1}, 3}\right)$ is interchanged with the parameter value of the second parameter combination $\left(p_{i_{2}, 3}\right)$.

The crossover process is not always successful. The combination of model parameter values has to be run on a basin state which was obtained with a different parameter set. The soil moisture profile as described through the kinematic approximation is unique for a given set of state variables, front positions and moisture content, and depends on model parameters (in particular, on parameter $f$ ). If parameter values are changed maintaining the state variable values (front position and moisture content) this could lead to numerical

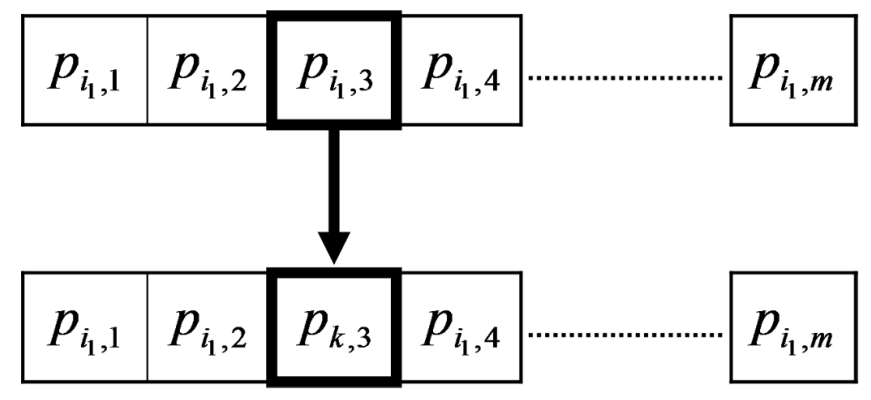

Fig. 2. Scheme of the mutation process. Model parameters for the parent at the top and model parameters for the child at the bottom.

instabilities in some cells, especially in those where the top front is close to the surface, because the moisture profile cannot be adapted to the new parameter values. Such instances were simply discarded in the GP data assimilation scheme.

\subsubsection{Mutation}

The mutation process is based on a random change in the genetic material or parameter values of one individual to produce a modified mutant child. Such mutation adds a perturbation in the parameter values of some individuals. This process differs from the crossover in that the mutation creates new parameter values, while crossover only interchanges the existing parameter values. Mutation tries to avoid the survival population being highly conditioned by the observations, despite the possible existence of errors in observations or changes in the basin response.

Mutation is also a stochastic process (Fig. 2). First, an ensemble individual is randomly selected from the parent population ( $i_{1}$ in the case of Fig. 2). Then, a model parameter is randomly taken from the $m$ model parameters $\left(p_{i_{1}, 3}\right.$ in the example shown in Fig. 2). Finally, perturbations in the value of the model parameter of that individual are produced to obtain the mutated child $\left(p_{k, 3}\right)$. For the sake of simplicity, as small perturbation magnitudes around the initial parameter value are generated, perturbations are simulated by a random normal distribution $N(0, \sigma)$ instead of utilising the distribution functions found as result of the calibration process (Eq. 9).

$f_{N}(x)=\frac{1}{\sigma \sqrt{2 \pi}} \exp \left[-\frac{x^{2}}{2 \sigma^{2}}\right]$

where $x$ is the value of the parameter and $\sigma$ is the standard deviation.

Perturbations are unbiased with the objective of them being centred on the value of the parent parameter value. Perturbation dispersion is fixed for each parameter by a given standard deviation $(\sigma)$. However, the final magnitude of the perturbation depends on the magnitude of the parent parameter value, which is multiplied by the result of the normal randomisation in order to obtain larger perturbations for larger 
values of parameters. The $\sigma$ value for each parameter should be of a sufficient magnitude to give flexibility to the forecast model, while small enough to avoid higher uncertainties. A sensitivity analysis is conducted to fix the $\sigma$ values.

\subsection{Measures for testing the forecast performance}

The comparison of each forecast needs certain measures that quantify the bias, accuracy and uncertainty of the forecast results. Two such measures were selected to validate the forecasts. The bias of the results was quantified by a modification of the Nash-Sutcliffe efficiency $\left(\operatorname{NSE}\left(\tilde{y}^{\prime}\right)\right)$ coefficient that compares the utility of the median of the forecasts with that of the temporal mean of the observations $(\bar{y}) \operatorname{NSE}\left(\tilde{y}^{\prime}\right)$ :

$$
\operatorname{NSE}\left(\tilde{y}^{\prime}\right)=1.0-\frac{\sum_{t=1}^{N}\left[y_{t}-\tilde{y}_{t}^{\prime}\right]^{2}}{\sum_{t=1}^{N}\left[y_{t}-\bar{y}\right]^{2}},
$$

where $\tilde{y}_{t}^{\prime}$ is the forecast median or value with a probability of 0.5 at time $t$. NSE $\left(\tilde{y}^{\prime}\right)$ has an optimal value of 1.0; a value of 0 indicates that a forecast using the mean of the observation for all time steps will have the same utility as the result of the forecast; and values below 0 indicate results are worse than the prognosis by the mean of the medians.

The accuracy of the results was quantified by the inclusion coefficient $[\mathrm{CR}(\alpha)]$, which assess the ability of the model to include observed flow values within the prediction intervals of forecasts associated with a confidence level $\alpha$ by calculating the proportion of time intervals in which the observed flow falls within the prediction interval over the total number of time intervals (Montanari, 2005):

$\mathrm{CR}(\alpha)=\frac{\sum_{t=1}^{N} I\left[y_{t}\right]}{N}$,

where $I\left[y_{t}\right]$ is 1 if the observed flow value falls within the prediction interval at time $t$, and is 0 otherwise.

The uncertainty of the model was quantified by the coefficient of variation $(\mathrm{CV})$ of forecasts at each time step, which measures the dispersion of results. A lower dispersion is preferred, as the forecast increases its precision.

\subsection{Setup of the forecast models}

Both forecast models have the following characteristics. The size of the forecast ensemble $\left(N_{\mathrm{e}}\right)$ is 100 simulations. The time step length of RIBS model run $\left(\Delta t_{\mathrm{r}}\right)$ is $15 \mathrm{~min}$, as it was found to be the optimum time resolution by Atencia et al. (2011). The time step length of the simulation $\left(\Delta t_{\mathrm{s}}\right)$ and forecasting $\left(\Delta t_{\mathrm{f}}\right)$ loops is two hours. The observed rainfall is considered as forecast rainfall.

The forecast model with data assimilation has further characteristics. For each time step of the simulation loop, natural

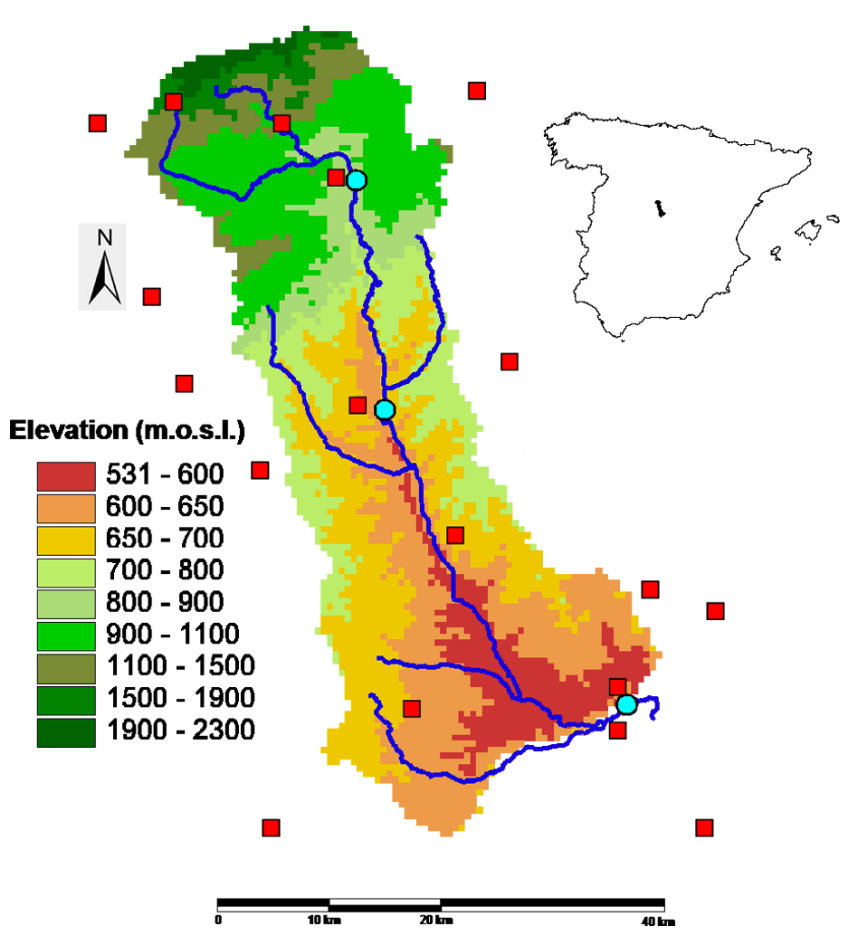

Fig. 3. Location of the Manzanares River basin. Circles are streamflow gauge stations, from north to south: Santillana reservoir, El Pardo reservoir and Rivas Vaciamadrid. Squares are precipitation gauge stations. The figure in the upper right corner represents the basin location within Spain.

selection is applied by means of the selection process. The survival rate was fixed at $50 \%$; hence, 50 individuals will live and 50 will die from each generation. The number of selected individuals $\left(N_{\mathrm{s}}\right)$ is fixed at 50 . To keep the size of the forecast ensemble at 100, 50 new individuals are generated each time step by crossover and mutation by the same rate. The number of new individuals created by crossover $\left(N_{\mathrm{c}}\right)$ is 25 and the number of new individuals created by mutation $\left(N_{\mathrm{m}}\right)$ is 25 .

\section{Case study}

The Manzanares River basin was selected as a case study. The river is located in the centre of Spain and crosses the city of Madrid (Fig. 3), having a basin area of $1248 \mathrm{~km}^{2}$. The basin outlet was taken at the gauging station Rivas Vaciamadrid, as it is located very close to its confluence with the Jarama River.

Two reservoirs are located within the basin: the Santillana and El Pardo. The flood control process in these reservoirs was simulated by the volumetric assessment method (VAM), which is based on three principles: outflow discharge must be lower than inflow discharge at the rising limb of the inflow hydrograph; outflow discharge should increase with increases in inflow discharge; and the percentage increase in 
Table 1. Flood events in the Manzanares River basin.

\begin{tabular}{lrrrr}
\hline Event & $\begin{array}{r}\text { Maximum } \\
\text { intensity } \\
(\mathrm{mm} / 15 \mathrm{~min})\end{array}$ & $\begin{array}{r}\text { Maximum } \\
\text { intensity } \\
(\mathrm{mm} / 30 \mathrm{~min})\end{array}$ & $\begin{array}{r}\text { Rainfall } \\
\text { volume } \\
\left(\mathrm{hm}^{3}\right)\end{array}$ & $\begin{array}{r}\text { Flow } \\
\text { volume } \\
\left(\mathrm{hm}^{3}\right)\end{array}$ \\
\hline 14 April 2003 & 5.50 & 9.40 & 20.91 & 1.71 \\
5 December 2003 & 3.60 & 5.40 & 28.42 & 4.40 \\
21 February 2004 & 2.20 & 4.40 & 23.23 & 6.80 \\
28 April 2004 & 5.20 & 9.80 & 13.76 & 3.12 \\
\hline
\end{tabular}

outflow discharge relative to the inflow should increase with reservoir level (Girón, 1988).

The Manzanares River basin has a Mediterranean climate with a wet period from autumn to spring and a dry period in summer. Therefore, most of flood events occur during the wet period. The time of concentration of the Manzanares River basin is $22 \mathrm{~h}$. However, the city of Madrid is located downstream the El Pardo reservoir, being the time of concentration of this subbasin equal to eight hours.

Maps of runoff and slope directions were generated from a digital elevation model (DEM) of $100-\mathrm{m}$ cell width. The DEM was generated from maps with a horizontal scale of $1: 250000$ and elevation resolution of $1 \mathrm{~m}$.

Spatially distributed rainfall events were characterised from data recorded at 18 rainfall gauging stations that belong to the SAIH network; seven are located within the basin of the Manzanares River, and the other 11 are in surrounding areas within its area of influence. Spatial distribution of rainfall was estimated by the inverse distance weighted interpolation method, which uses the weighted sum of the rainfall observed at gauge stations in terms of the inverse of distance to known points. Flow data were recorded in three gauging stations located in the Manzanares River: the Santillana and El Pardo dams and the Rivas Vaciamadrid station. The comparison between both forecast models was focused on the observed discharges recorded at the outlet, for the sake of simplicity. Four flood events were considered and the corresponding main characteristics are shown in Table 1.

\section{Results}

\subsection{Sensitivity analysis on the variation of mutation perturbations}

The mutation process is simulated by random perturbations, with a magnitude sampled from a normal distribution. Perturbation dispersion is fixed for each parameter by $\sigma$. A sensitivity analysis is carried out to fix a $\sigma$ value for each parameter so that dispersions are big enough to provide flexibility to the forecast model, while small enough to avoid higher uncertainties. In addition, the $\sigma$ parameter of the perturbations used in the mutation process gives the mutation magnitude or magnitude of parameter changes around its initial value. As these changes are slight in comparison with the parameter

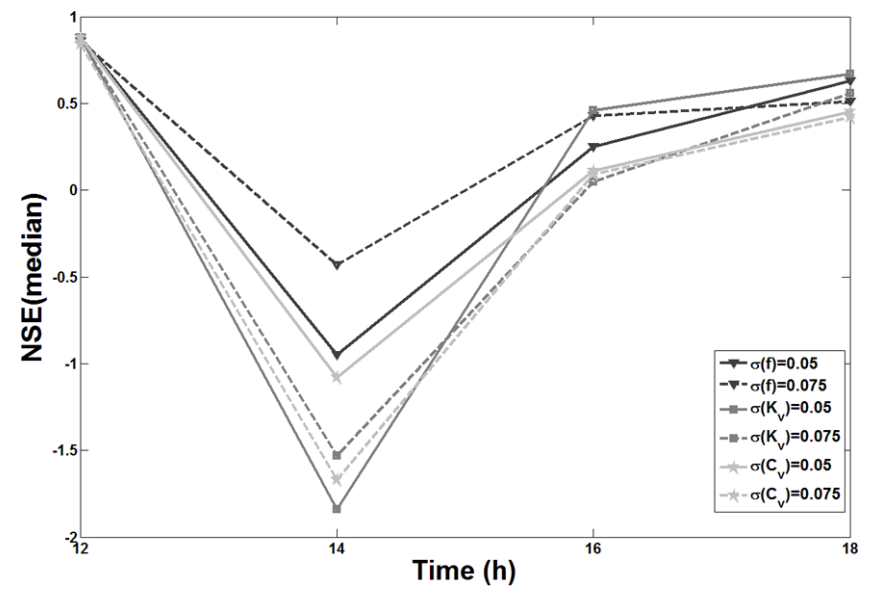

Fig. 4. Comparison of forecast model results by the $\operatorname{NSE}\left(\tilde{y}^{\prime}\right)$ for different dispersion in the mutation process.

Table 2. Results of the $\operatorname{NSE}\left(\tilde{y}^{\prime}\right)$ for different dispersion in the mutation process.

\begin{tabular}{lrrrr}
\hline Forecast & $t=12 \mathrm{~h}$ & $t=14 \mathrm{~h}$ & $t=16 \mathrm{~h}$ & $t=18 \mathrm{~h}$ \\
\hline$\sigma(f)=0.05$ & 0.88 & -0.95 & 0.25 & 0.63 \\
$\sigma(f)=0.075$ & 0.86 & -0.43 & 0.43 & 0.51 \\
$\sigma\left(K_{\mathrm{V}}\right)=0.05$ & 0.88 & -1.84 & 0.46 & 0.67 \\
$\sigma\left(K_{\mathrm{V}}\right)=0.075$ & 0.87 & -1.53 & 0.05 & 0.56 \\
$\sigma\left(C_{\mathrm{V}}\right)=0.05$ & 0.88 & -1.08 & 0.11 & 0.45 \\
$\sigma\left(C_{\mathrm{V}}\right)=0.075$ & 0.84 & -1.67 & 0.09 & 0.42 \\
\hline
\end{tabular}

ranges obtained in the calibration process, a different distribution function from that used in the calibration can be accepted.

For the following forecasting time step the RIBS model is run with the new parameter set, though starting from a basin state obtained with the parent parameter set. Since moisture profiles correspond to different parameter values from those applied in the new simulation, a large change of parameter values may lead to instabilities in the resolution of differential equations of the RIBS model, and therefore $\sigma$ values were limited to 0.1 . Moreover, given that values higher than 0.1 lead to very high dispersion, influence of $\sigma$ equal to 0.05 and 0.075 in forecast results was tested. The sensitivity analysis entailed running the forecast model with data assimilation, applying the mutation process to only one of the model parameters, fixing $\sigma$ for this model parameter and setting $\sigma$ equal to zero for the other two parameters. The flood event that occurred in February 2004 was selected to conduct the sensitivity analysis. The results are shown in Table 2 and Fig. 4.

At first, it can be seen that the best results are achieved by a $\sigma$ value of 0.075 for the $f$ parameter and that in the first time step there are no substantial differences among forecasts because the rising limb of the flood hydrograph is just 

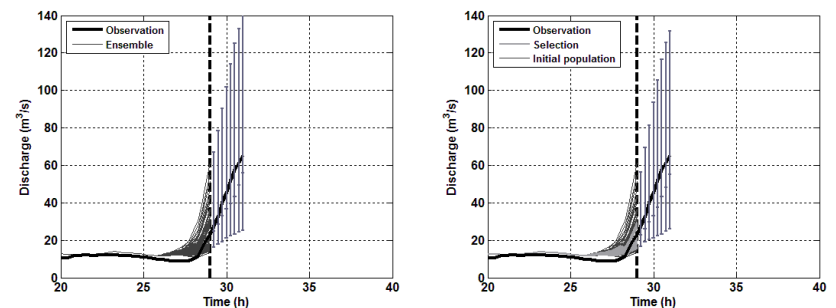

(a)
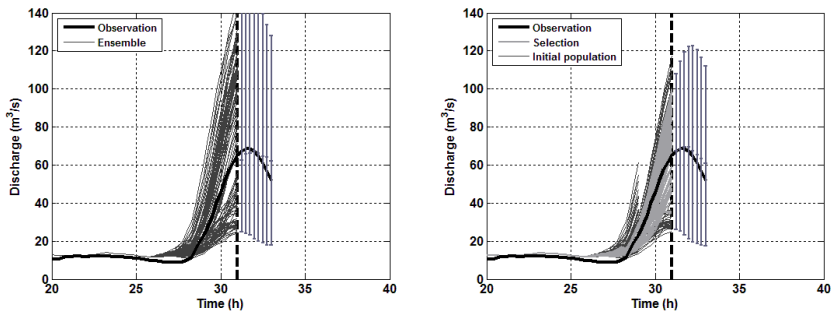

(b)
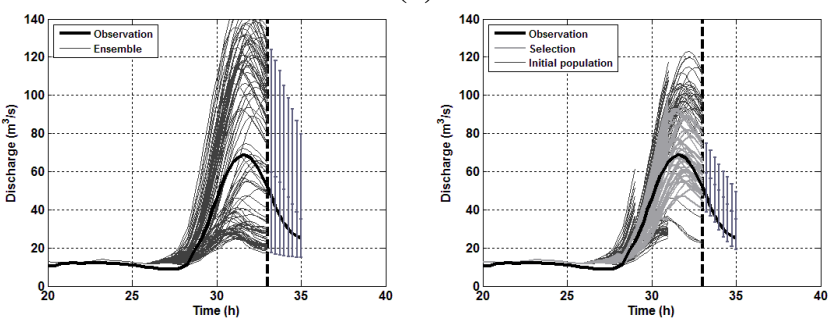

(c)
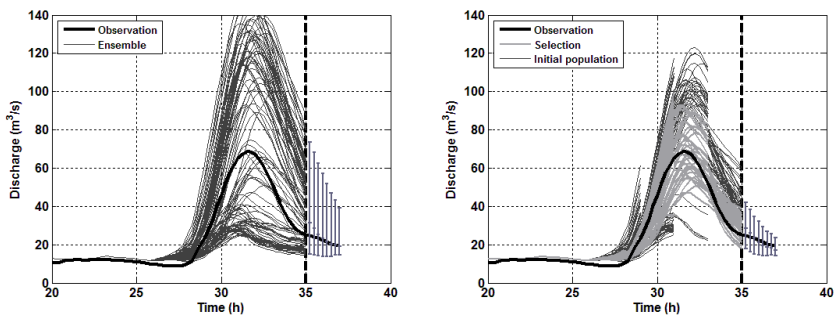

(d)

Fig. 5. Results of the forecast models for the April 2003 flood event. The vertical dashed line is the current time step. Forecasts are expressed by the median and the prediction limits for a confidence level of $5 \%$. The first column shows the results of the forecast model without data assimilation and the second column the forecast model with data assimilation. The rows show forecasts by current time step: (a) $t=29 \mathrm{~h}$; (b) $t=31 \mathrm{~h}$; (c) $t=33 \mathrm{~h}$; (d) $t=35 \mathrm{~h}$.

beginning. By comparing the results of the $f$ parameter for both $\sigma$ values it can be seen that a $\sigma$ value equal to 0.05 only slightly improves the forecast in the last time step $(t=18 \mathrm{~h})$ when the peak has passed and the forecast is less important. Therefore, a dispersion given by a $\sigma$ value equal to 0.075 is selected for the $f$ parameter.

Regarding the $K_{\mathrm{v}}$ parameter, there are no significant differences between the $\sigma$ values in the first two time steps. However, a $\sigma$ value of 0.05 gives better results at the time of peak, with an improvement of 0.40 in the $\operatorname{NSE}\left(\tilde{y}^{\prime}\right)$. A $\sigma$
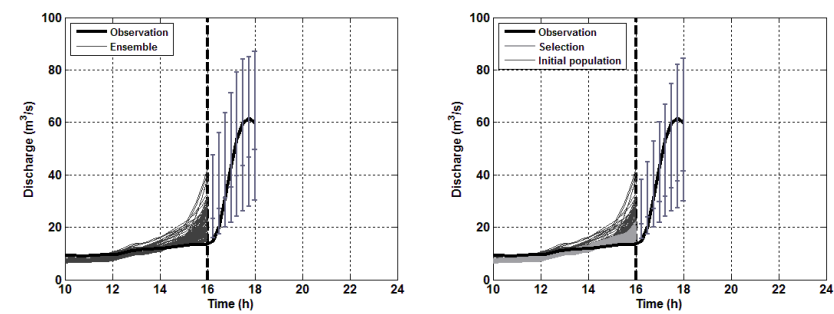

(a)
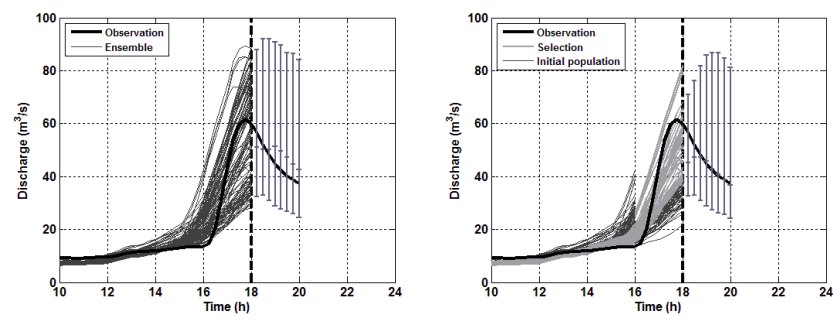

(b)
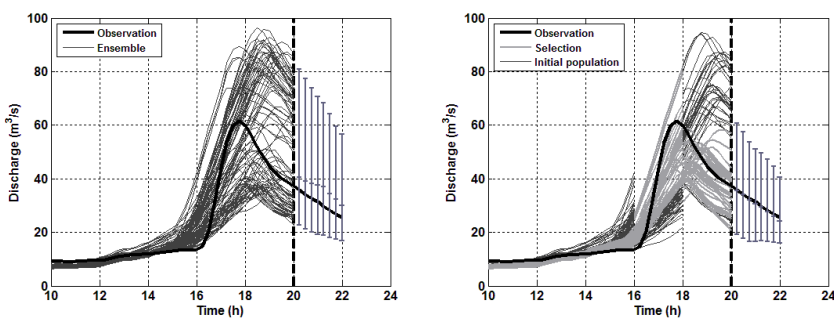

(c)

Fig. 6. Results of the forecast models for the December 2003 flood event. The vertical dashed line is the current time step. Forecasts are expressed by the median and the prediction limits for a confidence level of $5 \%$. The first column shows the results of the forecast model without data assimilation and the second column the forecast model with data assimilation. The rows show forecasts by current time step: (a) $t=16 \mathrm{~h}$; (b) $t=18 \mathrm{~h}$; (c) $t=20 \mathrm{~h}$.

value of 0.05 is selected to represent the dispersion in the mutation step for the $K_{\mathrm{v}}$ parameter. $C_{\mathrm{v}}$ parameter shows better results for a $\sigma$ value of 0.05 in all time steps, so this $\sigma$ is selected to represent the dispersion of mutations.

\subsection{Forecast improvement by data assimilation}

Once mutation dispersion was fixed for each model parameter, improvement of the forecast model with data assimilation based on GP over the model without data assimilation was assessed. The models were compared in four observed events.

\subsubsection{The April 2003 flood event}

Both forecast models were applied to the flood event that occurred in April 2003 (Table 3 and Fig. 5). The models were initialised at time step $20 \mathrm{~h}$ and the first forecast was made at time step $29 \mathrm{~h}$. This first operational time step had a length of $9 \mathrm{~h}$, so the beginning of the basin response to the observe 
Table 3. Results of the validation measures for the April 2003 flood event.

\begin{tabular}{llrrrr}
\hline Forecast & & $t=129 \mathrm{~h}$ & $t=131 \mathrm{~h}$ & $t=133 \mathrm{~h}$ & $t=135 \mathrm{~h}$ \\
\hline \multirow{5}{*}{ Forecast without data assimilation } & $\mathrm{NSE}\left(\tilde{y}^{\prime}\right)$ & $\mathbf{0 . 8 2}$ & -0.12 & -1.26 & -2.19 \\
& $\mathrm{CR}(\alpha=5)$ & 1.00 & 1.00 & 1.00 & 1.00 \\
& $\mathrm{CV}$ & 0.49 & 0.60 & 0.59 & 0.48 \\
\hline \multirow{5}{*}{ Forecast with data assimilation } & $\mathrm{NSE}\left(\tilde{y}^{\prime}\right)$ & 0.74 & $\mathbf{0 . 5 4}$ & $\mathbf{- 1 . 1 4}$ & $\mathbf{- 1 . 5 7}$ \\
& $\mathrm{CR}(\alpha=5)$ & 1.00 & 1.00 & 1.00 & 1.00 \\
& $\mathrm{CV}$ & $\mathbf{0 . 4 4}$ & $\mathbf{0 . 4 5}$ & $\mathbf{0 . 2 9}$ & $\mathbf{0 . 2 2}$ \\
\hline
\end{tabular}

rainfall could be used to quantify the ability of each parameter combination to reproduce the observed hydrograph.

The bias of both models was measured by the $\operatorname{NSE}\left(\tilde{y}^{\prime}\right)$. It can be seen that its results in the first time step are similar for each model. However, the forecast model with data assimilation improves the results of the model without data assimilation in the next time steps in terms of bias. In the last two time steps both models have negative values of the $\operatorname{NSE}\left(\tilde{y}^{\prime}\right)$, as they give discharges higher than observations.

The accuracy of the models is similar from the results of the $\mathrm{CR}$ for a confidence level of $5 \%(\mathrm{CR}(\alpha=5))$. It can be seen that the observed hydrograph lies between the prediction limits for the given confidence level in all time steps.

A notable difference between the models can be seen in terms of dispersion. A significant reduction in the uncertainty of the forecast is achieved by the GP model in all time steps, as the $\mathrm{CV}$ is reduced up to half in the last time steps. The data assimilation technique is able to reduce the dispersion of the forecast, discarding the parameter combinations that yield worse results and selecting the parameter combinations that yield results more similar to the observations. This means that the data assimilation technique is able to reproduce the observed hydrograph during the flood event.

\subsubsection{The December 2003 flood event}

In the December 2003 flood event, the models were initialised at time step $10 \mathrm{~h}$ and the first forecast was made at time step $16 \mathrm{~h}$ (Table 4 and Fig. 6). In this case, the forecast model based on GP obtains the best results in the last time step in terms of bias. However, the models have similar results in terms of accuracy. The observed hydrograph lies between the prediction intervals in all time steps, except at the beginning of the first time step where the models cannot be adapted to the observations.

In terms of dispersion, the GP model achieves better results as it has smaller values of the CV in all time steps, with the difference being higher in the last time step. It is clear that the GP model always gives smaller dispersions than the model without data assimilation, as the former tries to adapt to the observations.
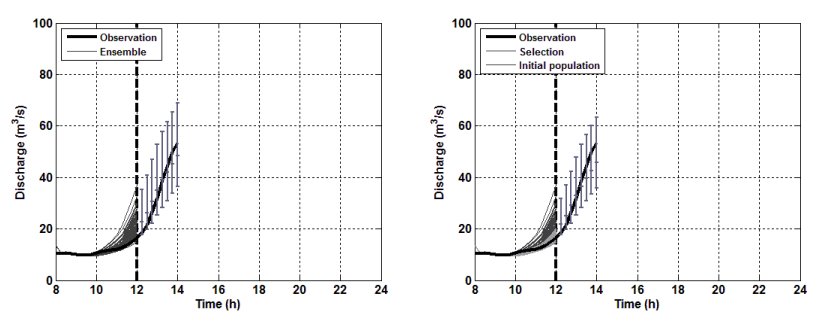

(a)
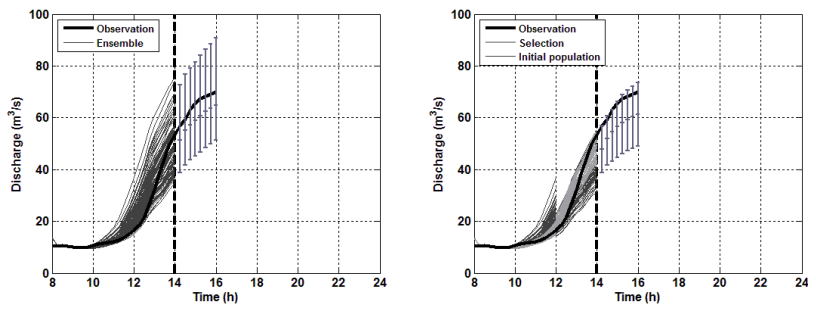

(b)
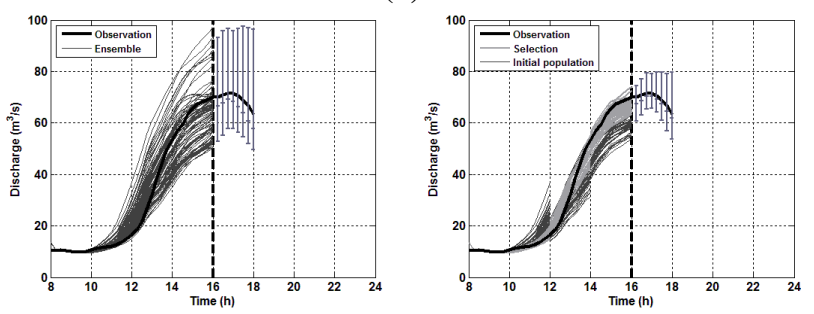

(c)
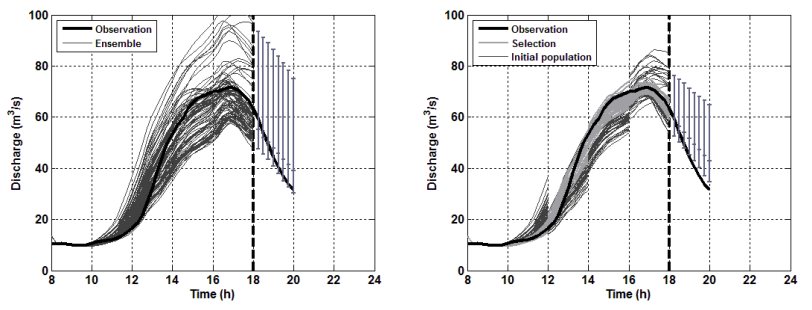

(d)

Fig. 7. Results of the forecast models for the February 2004 flood event. The vertical dashed line is the current time step. Forecasts are expressed by the median and the prediction limits for a confidence level of $5 \%$. The first column shows the results of the forecast model without data assimilation and the second column the forecast model with data assimilation. The rows show forecasts by current time step: (a) $t=12 \mathrm{~h}$; (b) $t=14 \mathrm{~h}$; (c) $t=16 \mathrm{~h}$; (d) $t=18 \mathrm{~h}$. 
Table 4. Results of the validation measures for the December 2003 flood event.

\begin{tabular}{llrrr}
\hline Forecast & & $t=16 \mathrm{~h}$ & $t=18 \mathrm{~h}$ & $t=20 \mathrm{~h}$ \\
\hline \multirow{5}{*}{ Forecast without data assimilation } & $\mathrm{NSE}\left(\tilde{y}^{\prime}\right)$ & $\mathbf{0 . 6 7}$ & $\mathbf{0 . 3 2}$ & -1.21 \\
& $\mathrm{CR}(\alpha=5)$ & 0.78 & 1.00 & 1.00 \\
& $\mathrm{CV}$ & 0.34 & 0.38 & 0.40 \\
\hline \multirow{5}{*}{ Forecast with data assimilation } & $\mathrm{NSE}\left(\tilde{y}^{\prime}\right)$ & 0.28 & 0.08 & $\mathbf{0 . 9 6}$ \\
& $\mathrm{CR}(\alpha=5)$ & 0.78 & 1.00 & 1.00 \\
& $\mathrm{CV}$ & $\mathbf{0 . 3 1}$ & $\mathbf{0 . 3 4}$ & $\mathbf{0 . 3 2}$ \\
\hline
\end{tabular}

\subsubsection{The February 2004 flood event}

Each forecast model was applied to the flood event that occurred in February 2004 (Table 5 and Fig. 7). The models were initialised at time step eight hours and the first forecast was made at time step $12 \mathrm{~h}$.

The bias of each model was measured by the $\operatorname{NSE}\left(\tilde{y}^{\prime}\right)$. It can be seen that bias results in the first time step are similar for each model, though bias results in the second and fourth time step are better for the model without data assimilation, while the GP model has better results in the third time step. However, the accuracy of the models is similar in terms of the $\operatorname{CR}(\alpha=5)$. It can be seen that the observed hydrograph lies between the prediction limits for the given confidence level, except in the last time step where the GP forecast gives somewhat overestimated results.

A notable difference in terms of dispersion can be also observed, as in the case of the previous events. A reduction in the uncertainty of the forecast is achieved by the GP model in all time steps. The difference in the first time step is very low, though it does increase in the rest of time steps up to a half in the last two time steps, with the $\mathrm{CV}$ of the forecast model without data assimilation being significantly higher than the forecast model based on GP.

\subsubsection{The April 2004 flood event}

In the April 2004 flood event, the models were initialised at time step $10 \mathrm{~h}$ and the first forecast made at time step $20 \mathrm{~h}$ (Table 6 and Fig. 8).

The results show that the observation lies outside the selected members in some time steps. This is caused by the use of the RMSE to select the best members. This objective function gives higher penalties to higher deviations following a square law. As a result, some members that have great deviations in some time steps are discarded.

In this flood event, the bias of the GP model is better than the bias of the model without data assimilation, mainly in the last two time steps where the GP model highly improves the results. The accuracy of the models is similar in terms of the $\mathrm{CR}(\alpha=5)$ and the GP improves the forecast in terms of uncertainty reduction, as in the previous cases. A notable difference in terms of dispersion can be observed, mainly in
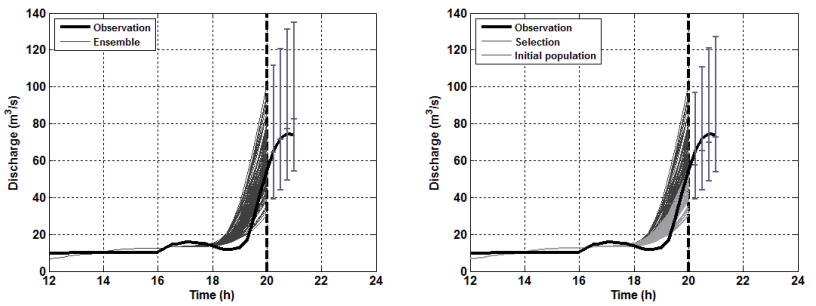

(a)
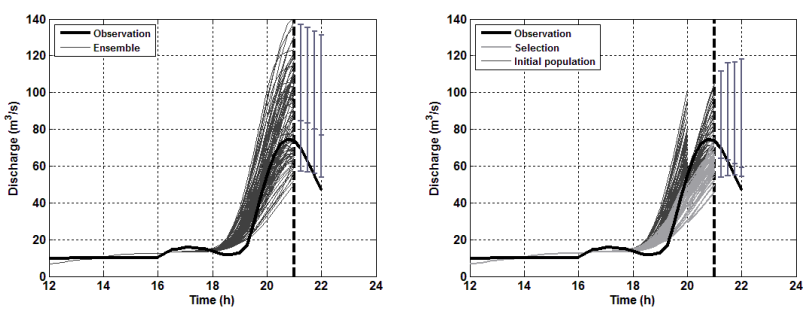

(b)
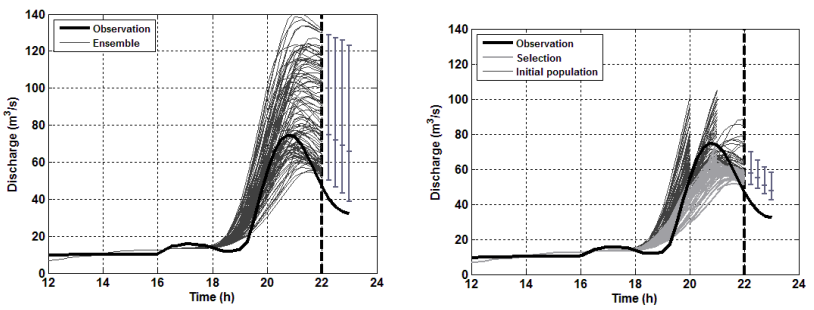

(c)

Fig. 8. Results of the forecast models for the April 2004 flood event. The vertical dashed line is the current time step. Forecasts are expressed by the median and the prediction limits for a confidence level of $5 \%$. The first column shows the results of the forecast model without data assimilation and the second column the forecast model with data assimilation. The rows show forecasts by current time step: (a) $t=20 \mathrm{~h}$; (b) $t=21 \mathrm{~h}$; (c) $t=22 \mathrm{~h}$.

the last time step where the dispersion reduction is higher than two thirds.

\section{Conclusions}

Data assimilation techniques can improve the performance of forecast models if an adaptive algorithm updates model parameters from observations. The improvements obtained 
Table 5. Results of the validation measures for the February 2004 flood event.

\begin{tabular}{llrrrr}
\hline Forecast & & $t=12 \mathrm{~h}$ & $t=14 \mathrm{~h}$ & $t=16 \mathrm{~h}$ & $t=18 \mathrm{~h}$ \\
\hline \multirow{5}{*}{ Forecast without data assimilation } & $\mathrm{NSE}\left(\tilde{y}^{\prime}\right)$ & $\mathbf{0 . 9 0}$ & $\mathbf{0 . 0 5}$ & -1.98 & $\mathbf{0 . 7 6}$ \\
& $\mathrm{CR}(\alpha=5)$ & 1.00 & 1.00 & 1.00 & $\mathbf{1 . 0 0}$ \\
& $\mathrm{CV}$ & 0.19 & 0.17 & 0.15 & 0.21 \\
\hline \multirow{5}{*}{ Forecast with data assimilation } & $\mathrm{NSE}\left(\tilde{y}^{\prime}\right)$ & 0.88 & -1.31 & $\mathbf{0 . 3 4}$ & 0.48 \\
& $\mathrm{CR}(\alpha=5)$ & 1.00 & 1.00 & 1.00 & 0.44 \\
& $\mathrm{CV}$ & $\mathbf{0 . 1 6}$ & $\mathbf{0 . 1 1}$ & $\mathbf{0 . 0 6}$ & $\mathbf{0 . 1 1}$ \\
\hline
\end{tabular}

Table 6. Results of the validation measures for the April 2004 flood event.

\begin{tabular}{llrrr}
\hline Forecast & & $t=20 \mathrm{~h}$ & $t=21 \mathrm{~h}$ & $t=22 \mathrm{~h}$ \\
\hline \multirow{3}{*}{ Forecast without data assimilation } & $\operatorname{NSE}\left(\tilde{y}^{\prime}\right)$ & $\mathbf{0 . 6 4}$ & -3.79 & -38.31 \\
& $\operatorname{CR}(\alpha=5)$ & 1.00 & 0.60 & 0.00 \\
& $\mathrm{CV}$ & 0.26 & 0.28 & 0.34 \\
\hline \multirow{3}{*}{ Forecast with data assimilation } & $\mathrm{NSE}\left(\tilde{y}^{\prime}\right)$ & 0.40 & $\mathbf{0 . 3 8}$ & $\mathbf{- 5 . 9 8}$ \\
& $\mathrm{CR}(\alpha=5)$ & 1.00 & 0.60 & 0.00 \\
& $\mathrm{CV}$ & $\mathbf{0 . 2 5}$ & $\mathbf{0 . 2 1}$ & $\mathbf{0 . 1 1}$ \\
\hline
\end{tabular}

with the sequential data assimilation technique presented in this paper were assessed by comparing the performance of a forecast model without data assimilation with that of a forecast model with data assimilation. The Manzanares River basin was selected as a case study and the RIBS model as a rainfall-runoff model. Spatially distributed observed rainfall was used as forecast rainfall in order to assess the performance of each forecast model without it being conditioned to the reliability of rainfall forecasts. In this paper, spatially distributed rainfall was estimated from data recorded at rainfall gauging stations. However, rainfall maps recorded by the radar network could be used if available. Furthermore, if new products exist, such as quantitative precipitation estimation or quantitative precipitation forecasts, they could be also used in the proposed forecast model.

The first forecast model, without data assimilation, was based on the results of a probabilistic calibration, which was conducted in a previous work on the selected river basin (Mediero et al., 2011). The probabilistic calibration gave as a result a probability density function for each influential parameter of the RIBS model, with the aim of considering different hydrological basin behaviours identified from the observed flood events. Such parameter characterisation is suitable for flood forecasting, as the objective functions used in the calibration process were selected in order to take the most important aspects of the hydrograph for real-time flood forecasting into account. This first forecast model does not use any assimilation technique from new observed data.

The second forecast model, with data assimilation, reduces the spread of the ensemble of the first model by using an adaptive model based on genetic programming. Data assimilation is conducted by three steps: a selection step to find the parents or model parameter combinations that lead to a better fit with the observations, a crossover step to simulate the creation of new parameter combinations from interchanging parameter values between parents, and the mutation step to simulate random changes in the parameter values of parents to create new children. This forecast model takes the results of the probabilistic calibration as a starting point, though the adaptive technique is able to reproduce the observed hydrograph and allows the model to be adapted to changes in basin response during the flood event.

The models were applied to four flood events that occurred in the Manzanares River basin. The accuracy of the models is similar, as the observed hydrograph lies between the prediction limits in the majority of the time steps. Although there are further differences in terms of bias, the most important improvement of the forecast model based on genetic programming was found to be in terms of dispersion or forecast uncertainty. The sequential model reduces the dispersion of forecasts significantly, with the dispersion being reduced by a half in most cases. It can hence be concluded that the introduction of a data assimilation scheme based on genetic programming improves the results of a forecast model based on calibration over observed events.

Acknowledgements. The authors wish to acknowledge support from project DRIHM-Distributed Research Infrastructure for Hydro-Meteorology, funded by the European Commission through Grant Agreement No. 283568, and project MODEXPhysically-based modelling of extreme hydrologic response under a probabilistic approach. Application to Dam Safety Analysis (CGL2011-22868), funded by the Spanish Ministry of Science and Innovation (now the Ministry of Economy and Competitiveness). 
Edited by: N. Rebora

Reviewed by: R. Rudari, M. C. Llasat, and two anonymous referees

\section{References}

Angeline, P. J., Saunders, G. M., and Pollack, J. B.: An evolutionary algorithm that constructs recurrent neural networks, IEEE T. Neural Networ., 5, 54-65, 1994.

Atencia, A., Mediero, L., Llasat, M. C., and Garrote, L.: Effect of radar rainfall time resolution on the predictive capability of a distributed hydrologic model, Hydrol. Earth Syst. Sci., 15, 38093827, doi:10.5194/hess-15-3809-2011, 2011.

Awwad, H. M. and Valdés, J. B.: Adaptive parameter estimation for multi-site hydrologic forecasting, J. Hydraul. Eng., 118, 12011221, 1992.

Aytek, A. and Alp, M.: An application of artificial intelligence for rainfall-runoff modelling, J. Earth Syst. Sci., 117, 145-155, 2008.

Babovic, V. and Keijzer, M.: Rainfall runoff modelling based on genetic programming, Nord. Hydrol., 33, 331-346, 2002.

Beven, K. J.: Infiltration into a class of vertically non-uniform soils, Hydrol. Sci. J., 29, 425-434, 1984.

Beven, K. J.: A manifesto for the equifinality thesis, J. Hydrol., 320, 18-36, 2006.

Bras, R. L. and Rodriguez-Iturbe, I.: Random functions and hydrology. Addison-Wesley, Reading, Massachusetts, USA, 1985.

Cabral, M. C., Garrote, L., Bras, R. L. and Entekhabi, D.: A kinematic model of infiltration and runoff generation in layered and sloped soils, Adv. Water Resour., 15, 311-324, 1992.

Clark, M. P., Rupp, D. E., Woods, R. A., Zheng, X., Ibbitt, R. P., Slater, A. G. Schmidt, J., and Uddstrom, M. J.: Hydrological data assimilation with the Ensemble Kalman Filter: use of streamflow observations to update states in a distributed hydrological model, Adv. Water Resour., 31, 1309-1324, 2008.

Dietrich, J., Schumann, A. H., Redetzky, M., Walther, J., Denhard, M., Wang, Y., Pfützner, B., and Büttner, U.: Assessing uncertainties in flood forecasts for decision making: prototype of an operational flood management system integrating ensemble predictions, Nat. Hazards Earth Syst. Sci., 9, 1529-1540, doi:10.5194/nhess-9-1529-2009, 2009.

Eiben, A. E. and Smith, J. E.: Introduction to Evolutionary computing. Springer, Natural Computing Series, 2007.

Elshorbagy, A., Corzo, G., Srinivasulu, S., and Solomatine, D. P.: Experimental investigation of the predictive capabilities of data driven modeling techniques in hydrology - Part 1: Concepts and methodology, Hydrol. Earth Syst. Sci., 14, 1931-1941, doi:10.5194/hess-14-1931-2010, 2010a.

Elshorbagy, A., Corzo, G., Srinivasulu, S., and Solomatine, D. P.: Experimental investigation of the predictive capabilities of data driven modeling techniques in hydrology - Part 2: Application, Hydrol. Earth Syst. Sci., 14, 1943-1961, doi:10.5194/hess-141943-2010, 2010b.

Evensen, G.: The Ensemble Kalman Filter: theoretical formulation and practical implementation, Ocean Dynam., 53, 343-367, 2003.

Evensen, G.: Sampling strategies and square root analysis schemes for the EnKF, Ocean Dynam., 54, 539-560, 2004.
Fogel, L. J., Owens, A. J., and Walsh, M. J.: Artificial Intelligence through simulated evolution. John Willey, New York, 1966.

Garrote, L. and Bras, R. L.: A distributed model for real-time forecasting using digital elevation models, J. Hydrol., 167, 279-306, 1995a.

Garrote, L. and Bras, R. L.: An integrated software environment for real-time use of a distributed hydrologic model, J. Hydrol., 167, 307-326, 1995b.

Girón, F.: The evacuation of floods during the operation of reservoirs, Transactions of the Sixteenth International Congress on Large dams, vol. 4, Report 25, 403-417, Beijing, China, 1988.

Holland, J. H.: Adaptation in natural and artificial systems, University of Michigan Press, Ann Arbor, Michigan, 1975.

Kalman, R. E.: A new approach to linear filtering and prediction problems, J. Basic Eng.-T ASME, 82, 35-45, 1960.

Khatibi, R., Ghorbani, M. A., Kashani, M. H., and Kisi, O.: Comparison of three artificial intelligence techniques for discharge routing, J. Hydrol., 403, 201-212, 2011.

Khu, S. T., Liong, S. Y., Babovic, V., Madsen, H., and Muttil, N.: Genetic programming and its application in real-time runoff forecasting, J. Am. Water Resour. As., 37, 439-451, 2001.

Kisi, O. and Shiri, J.: Precipitation forecasting using waveletgenetic programming and wavelet-neuro-fuzzy conjunction models, Water Resour. Manag., 25, 3135-3152, 2011.

Komma, J., Reszler, C., Blöschl, G., and Haiden, T.: Ensemble prediction of floods - catchment non-linearity and forecast probabilities, Nat. Hazards Earth Syst. Sci., 7, 431-444, doi:10.5194/nhess-7-431-2007, 2007.

Koza, J. R.: Genetic programming: on the programming of computers by means of natural selection, The MIT Press, Cambridge, Massachusetts, 1992.

Liu, Y. and Gupta, H. V.: Uncertainty in hydrologic modeling: toward an integrated data assimilation framework, Water Resour. Res., 43, W070401, doi:10.1029/2006WR005756, 2007.

Mediero, L., Garrote, L., and Martín-Carrasco, F. J.: Probabilistic calibration of a distributed hydrological model for flood forecasting. Hydrol. Sci. J., 56, 1129-1149, 2011.

Montanari, A.: Large sample behaviours of the generalized likelihood uncertainty estimation (GLUE) in assessing the uncertainty of rainfall-runoff simulations, Water Resour. Res., 41, W08406, doi:10.1029/2004WR003826, 2005.

Moradkhani, H., Hsu, K., Gupta, H. V., and Sorooshian, S.: Uncertainty assessment of hydrologic model states and parameters: sequential data assimilation using the particle filter. Water Resour. Res., 41, W070401, doi:10.1029/2004WR003604, 2005.

Parasuraman, K. and Elshorbagy, A.: Toward improving the reliability of hydrologic prediction: model structure uncertainty and its quantification using ensemble-based genetic programming framework, Water Resour. Res., 44, W12406, doi:10.1029/2007WR006451, 2008.

Pauwels, R. N. and De Lannoy, J. M.: Improvement of modeled soil wetness conditions and turbulent fluxes through the assimilation of observe discharge, J. Hydrometeorol., 7, 458-477, 2006.

Rabunal, J. R., Puertas, J., Suarez, J., and Rivero, D.: Determination of the unit hydrograph of a typical urban basin using genetic programming and artificial neural networks, Hydrol. Process., 21, 476-485, 2007.

Rebora, N., Ferraris, L., von Hardenberg, J., and Provenzale, A.: Rainfall downscaling and flood forecasting: a case study in the 
Mediterranean area, Nat. Hazards Earth Syst. Sci., 6, 611-619, doi:10.5194/nhess-6-611-2006, 2006.

Reichle, R. L. and Koster, R. D.: Assesing the impact of horizontal error correlations in backgorund fields on soil moisture estimation, J. Hydrometeorol., 3, 728-740, 2003.

Romanowicz, R. J., Young, P. C., and Beven, K. J.: Data assimilation and adaptive forecasting of water levels in the river Severn catchment, United Kingdom, Water Resour. Res., 42, W06407, doi:10.1029/2005WR004373, 2006.

Savic, D. A., Walters, G. A., and Davidson, J. W.: A Genetic Programming approach to rainfall-runoff modelling, Water Resour. Manag., 13, 219-231, 1999.

Schwefel, H. P.: Numerical optimization of computer models, John Wiley, Chichester, United Kingdom, 1981.

Shamir, E., Byong-Ju, L., Deg-Hyo, B., and Georgakakos, P.: Flood forecasting in regulated basins using the Ensemble Extended Kalman Filter with storage function method, J. Hydrol. Eng., 115, 1030-1044, 2010.

Szöllösi-Nagy, A.: Learning from your errors - if you can! Reflections on the value of hydrological forecasting models, UNESCOIHE, Delft, The Netherlands, 2009.

Taramasso, A. C., Gabellani, S., and Parodi, A.: An operational flash-flood forecasting chain applied to the test cases of the EU project HYDROPTIMET, Nat. Hazards Earth Syst. Sci., 5, 703710, doi:10.5194/nhess-5-703-2005, 2005.

Thirel, G., Martin, E., Mahfouf, J.-F., Massart, S., Ricci, S., Regimbeau, F., and Habets, F.: A past discharge assimilation system for ensemble streamflow forecasts over France - Part 2: Impact on the ensemble streamflow forecasts, Hydrol. Earth Syst. Sci., 14, 1639-1653, doi:10.5194/hess-14-1639-2010, 2010.
Vrugt, J. A., Gupta, H. V., Nualláin, B. Ó., and Bouten, W.: Realtime data assimilation for operational ensemble streamflow forecasting, J. Hydrometeorol., 7, 548-565, 2006.

Wagener, T., Wheater, H. S., and Gupta, H. V.: Rainfall-runoff modelling in gauged and ungauged catchments, London, Imperial College Press, 2004.

Wang, W. C., Chau, K. W., Cheng, C. T., and Qiu, L.: A comparison of performance of several artificial intelligence methods for forecasting monthly discharge time series, J. Hydrol., 374, 294-306, 2009a.

Wang, W. C., Xu, D., Qiu, L., and Ma, J.: Genetic programming for modelling long-term hydrological time series, Fifth International Conference on Natural Computation (ICNC), 4, 265-269, 2009 b.

Weerts, A. H. and El Serafy, G. Y. H.: Particle filtering and ensemble Kalman filtering for state updating with hydrological conceptual rainfall-runoff models, Water Resour. Res., 42, W09403, doi:10.1029/2005WR004093, 2006.

Weerts, A. H., Serafy, G. Y., Hummel, S., Dhondia, J., and Gerritsen, H.: Application of generic data assimilation tools (DATools) for flood forecasting purposes, Comput. Geosci., 36, 453-463, 2010.

Whigham, P. A. and Crapper, P. F.: Modelling rainfall-runoff using genetic programming, Math. Comput. Model., 33, 707-721, 2001.

Young, P. C.: Advances in real-time flood forecasting, Phil. Trans. R. Soc. London A, 360, 1433-1450, 2002. 